\title{
Realized effect of different selection criteria applied in breeding herds on performance in multiplier herds
}

\author{
Petr Humpolicek ${ }^{3 / *}$, Zdenek Tvrdon ${ }^{b}$
}

\begin{abstract}
$\begin{array}{llllllllllll}\text { A } & \text { B } & \mathbf{S} & \mathbf{T} & \mathbf{R} & \mathbf{A} & \mathbf{C} & \mathbf{T}\end{array}$
Different selection pressure on the litter size and growth performance traits has been applied on two subpopulations of Czech Large White sows (hyperprolific or normal). About 1933 farrows of 614 Czech Large White sows were included. The hypothesis that progeny of sows from hyperprolific subpopulation breed in multiplier herds have higher litter size traits was tested. Effects on the growth performance traits are reported so. Though the applied selection pressure on the number of functional nipples was low, these traits have remarkably increased in the HP subpopulation. Likewise, both studied growth performance traits reacted positively on the selection pressure and the differences between populations were highly significant. Surprisingly, no significant differences in litter size traits were found either in the first or in the first to fifth parity. The results outlined that the selection criteria applied in the breeding herds can efficiently increase the traits with middle or high heritability coefficients in multiplier herds. However, the selection seems rather non effective as far as the litter size traits are concerned, as the heritability coefficients of these are low and hence are influenced by crossbreeding. Using of auxiliary selection traits should be therefore considered for improvement of economic efficiency of multiplier herds.
\end{abstract}

\section{Introduction}

The litter size traits of sows depend on a complex of physiological, genetic and environmental factors. The effect of crossbreeding in the case of multiplication herd must be taken into consideration so. In addition the interactions between these factors must be considered. This complexity of combinations with many times confirmed low heritability coefficients $(0.05$ \pm 0.15 ) (Alfonso et al., 1997 and Wolf et al., 2008) and genetic correlations between prolificacy and carcass or growth traits result in the popular notion that genetic improvement of prolificacy cannot be effectively achieved. The use of genetic correlations between economically important traits is moreover complicated by non homogenous results of studies, which do not differ only in observed values but also seem to vary between populations (Hermesch et al, 2000). Although aforementioned factors complicate the effective selection for individual traits, the genetic progress in litter size has been recently achieved. This was mainly due to the use of family information, BLUP procedures and large population size. Additional methods like marker assisted selection (Distl, 2007) or introgression (Piyasatian et al, 2008), a combination of molecular data into the BLUP-AM procedure (Baruch and Weller, 2009) or hyperprolific lines creation (Bidanel and Ducos, 1994) have been considered and tested. The aim of this study is to evaluate the progress of prolificacy and carcass traits observed in multiplier herds in context of different selection criteria and breeding management. Our results describe the real 
differences observed in two subpopulations in breeding pyramid under commercial conditions.

\section{Material and methods}

\subsection{Experimental procedure}

Purebred Czech Large White sows and boars were used as parents. All sows were bred and raised at the one breeding herd. The sows in breeding herd were divided into either hyperprolific (HP) or normal (N) subpopulation. To be incorporated into the HP subpopulation, the sows had to meet the following criteria: excellent breeding value for litter size (number of piglets born alive in the second and subsequent litters) among the top 15\%; be on her first to third litter an average of 12 or more live-born piglets per litter; at least 7 functional nipples on either side, maximal back-fat thickness of $12 \mathrm{~mm}$ and the sow must be MHS negative. For testing the MHS status, the ryanodine receptor gene (RYR1) was used and the test was carried out according to Brenig and Brem (1992). Sows which failed to meet these criteria belonged to the $\mathrm{N}$ subpopulation. Breeding values for individual traits were computed for both populations using the same method. The aggregate breeding values were computed separately for both populations using different weight coefficients. The aggregate breeding value comprises of $60 \%$ $(\mathrm{HP})$ or $55 \%(\mathrm{~N})$ of litter size on the second and following litters, $30 \%(\mathrm{HP})$ or $40 \%(\mathrm{~N})$ of average daily gain and $10 \%$ $(\mathrm{HP})$ or $5 \%(\mathrm{~N})$ of lean meat content. In HP subpopulations aggregate breeding values were used for planned mating. All dams were mated with the purebred boars of Large White breed. In contrast to the sows from normal population the HP sows were mated or inseminated only with boars with excellent breeding values for reproduction ( $>5 \%$ of population). These schemes of selection and mating were practised for 4 years. During this time 614 gilts from FI offspring were moved to the multiplier herd were their performance were recorded and subsequently analysed. In multiplier herds the hyperprolific subpopulation progeny (HPP) or normal subpopulation progeny (NP) were bred. 97 from 614 gilts were HPP.

To multiplier herd the gilts were moved at age of six months. Two multiplier herds were included in the study. These herds were chosen because of identical herd management, housing system and diet used in order to minimize the variability caused by different herd. In spite of that the effect of herd remained significant and as such was included in the statistical model. In multiplier herds the sows were mated with Landrace boars.

\subsection{Animal management}

Throughout the growing period, the gilts had ad-libitum access to a standard corn-soybean meal diet $(13.0 \mathrm{ME} / \mathrm{kg} ; 9.8 \mathrm{~g}$ of lysine). The sows were fed twice a day. Animals were checked once daily (at 6:30) for oestrus by the back pressure test in the presence of an adult boar. In the case of insemination, the $80 \mathrm{ml}$ insemination doses containing 2.5 billions of normal sperm preserved by 7 day diluents were used. The inseminations (always with the presence of mature boar) as well as mating were carried out twice a day in 10-h intervals. All sows were checked for pregnancy on the 30th day after insemination by the sonograph test. The cornsoybean diet based on barley, wheat and soya was used for feeding during the pregnancy of sows $(12.6 \mathrm{ME} / \mathrm{kg} ; 160 \mathrm{~g}$ of crude protein; $6.6 \mathrm{~g}$ of lysine). Identical to the diet of pregnant sows the diet of nursing sows was corn-soybean diet based on barley, wheat and soya but with different parameters (13.0 $\mathrm{ME} / \mathrm{kg} ; 200 \mathrm{~g}$ of crude protein; $8 \mathrm{~g}$ of lysine).

2.3. Studied traits

Several performance traits were recorded in the FI offspring. The prolificacy was specified by the total number of piglets born (TNB; defined as the number of all fully formed fetuses expelled at farrowing, dead or alive), number of piglets born alive (NBA; defined as the number of piglets alive immediately after birth), number of piglets weaned (NW; defined as the number of piglets available on the 28th day of the piglets' age), age of sows at the first parity (AFP) and number of functional nipples (FN). As the traits describing the growth performance the ultrasonic back-fat thickness (BF; Sonomark 100) and lean meat content (LMC; calculated from ultrasonic measurements without any live weight preadjustment) were used.

\subsection{Statistical analyses}

Mixed linear models, using the procedure REML in SAS for Windows 9.1.2. were applied to estimate the differences between the performance of FI offspring. The choice of fixed factors included: the affiliation of the sow to the HP or N subpopulation; type of mating - natural mating of artificial insemination; year and season of litter; and parity number. The random effect of sires, dams and boars used for mating in multiplier herd was taken into account as the source of genetic variation. Furthermore, the back-fat thickness and age at first parity was used as linear regression in some models. Used models are defined in Table 1. The analyses of litter size traits (TNB; NBA; NW) were performed independently in the first and in the first to fourth parity.

Table 1

Specification of used models.

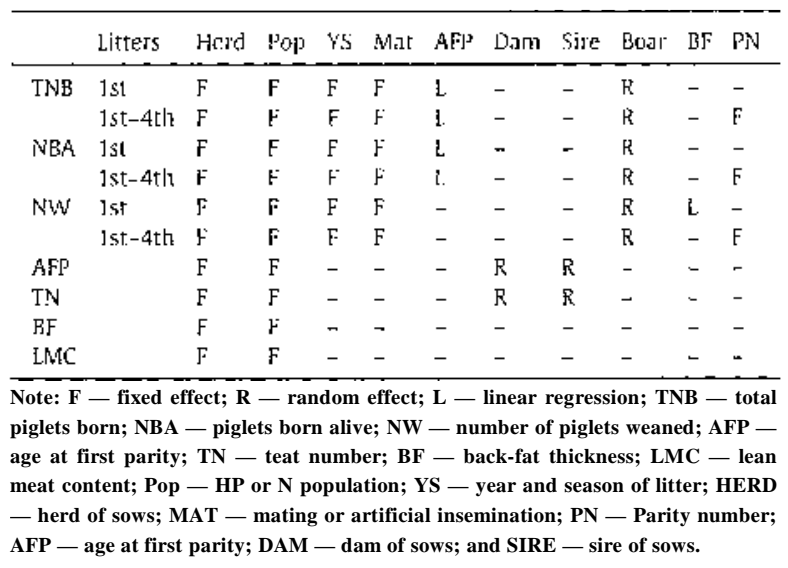




\section{Results and discussion}

A selection practice in the swine industry is similar worldwide and universally follows genetic evaluations for economically important traits. Albeit a remarkable progress realized by incorporation of pedigree information into the computation of estimated breeding value was achieved, a modification of selection criteria could further improve the economic profit in multiplier herds. One of key factors for different selection requirements in breeding and multiplier herd was introduced in the work of Wilton and Goddard (1996). Whereas at nucleus level the selection indices are linear, on the commercial level the selection indices can be non linear. This is caused by the effects which do not occur in nucleus as heterosis or on linear price girds. Thus, commercial animals are crossbreds but genetic selection is based on purebred performance. Likewise, the economic weights should also depend on the type of the crossbreeding system, the management system and the criteria of economic efficiency used in the production system (Wolfova et al, 2001). The fact that selection of parents in one type of mating system and environment may not optimize progeny performance in another type of system and environment, was described in the work of Weigel et al. (2001) or Mulder and Bijma (2005).

A general problem in comparing results from the literature is that there are only few studies concerning heritability at the same population. We chose only few studies performed at the same or similar population. In our study the hypothesis that hyperprolific subpopulation progeny (HPP) bred in multiplier herds have different performance than sows from normal subpopulation progeny (NP) was tested. The progresses in prolificacy traits, concretely litter size, were considered to be the most important reason for creation of hyperprolific subpopulation. The breeders expected that progress would be transferred into multiplier herds. In presented study no significant differences in the litter size traits neither on the first parity nor on the first to fourth parities (Table 2.) were observed between HPP and NP sows. This is in contrast to our hypothesis that higher selection pressure on the litter size should increase the litter size of progeny. These results can be assessed according to the results of study conducted by Wolf et al. (2008), which dealt with the heritability coefficients in the population of hyperprolific Czech Large White sows. The following heritability coefficients were computed: $0.13 \pm 0.018$; $0.14 \pm 0.020$ and $0.16 \pm 0.018$ for the total number of piglets bom; number of piglets born alive and number of piglets weaned respectively. Apart from zero effect on litter size traits we did not detect any effect on the age at first parity. The importance of selection on litter size traits is emphasized by the correlation with other important traits such as birth weight. Relatively high positive genetic correlation between these traits was found by Wolf et al. (2008), who conducted a detailed study on the litter size traits, and birth weight in hyperprolific Czech Large White sows. They detected positive genetic correlation (around 0.40) between the range of the birth weight with the total number of piglets born and the number of piglets born alive, whereas the genetic correlation with the number of piglets weaned was zero or close to zero.

Contrary to aforementioned traits for which no differences were detected, the number of functional nipples and both growth performance traits show significant differences
Table 2

Differences between sows of the HP or N population.

\begin{tabular}{|c|c|c|}
\hline & $N$ & $\mathrm{H} \Gamma^{\top}$ \\
\hline \multicolumn{3}{|l|}{ 1st litters } \\
\hline$N(614)$ & $\begin{array}{l}\text { Jerd } 1 \text { л }=402 \text {; } \\
\text { Herd } 11 \mathrm{n}=115\end{array}$ & $\begin{array}{l}\text { ] Herd [ } n=34 ; \\
\text { Herd II } n-63\end{array}$ \\
\hline TNB & $9.96 \pm 0.1982$ & $10.36 \pm 0.3672$ \\
\hline NDA & 9.65 上0.1907 & $10.16 \pm 0.3558$ \\
\hline$X W$ & $8.97 \pm 0.1618$ & $9.44 \pm 0.2970$ \\
\hline AFP & $375.05 \pm 3.3115$ & $374.86+6.6259$ \\
\hline$T . V$ & $14,57 \pm .0403^{4}$ & $14,79 \pm 0.0805^{11}$ \\
\hline $\mathrm{HF}$ & $1.02+0.0157^{8}$ & 0.92 上 $0.0314^{\mathrm{H}}$ \\
\hline $1 \mathrm{MC}$ & $60.34+0.1049^{\mathrm{a}}$ & $60.94 \pm 0.1994^{\mathrm{B}}$ \\
\hline \multicolumn{3}{|c|}{ 15t-4th litters } \\
\hline$N(1933)$ & $\begin{array}{l}\text { Herd } 1 \mathrm{n}=1357 \\
\text { Herd } 1 \mathrm{l}=319\end{array}$ & $\begin{array}{l}\text { Herd I } \mathrm{n}=89 \\
\text { Herd I[ } \mathrm{n}=168\end{array}$ \\
\hline TNE & $9.96 \pm 0.1978$ & $10.37 \pm 0.3665$ \\
\hline NBA & $9.64 \perp 0.1905$ & $10.18 \pm 0.3555$ \\
\hline $\mathrm{NW}$ & $8.97 \pm 0.1616$ & $9.45 \pm 0.2973$ \\
\hline
\end{tabular}

Note: TNB - total number of piglets born; NBA - number of piglets born alive, NW - number of piglets weaned; AFP - age at first parity; TN - teat number; BF — back-fat thickness; and LMC — lean meat content. Values with the different superscripts show significance level within rows: $\mathbf{P}<0.01\left({ }^{\mathrm{A}},{ }^{\mathrm{B}}\right)$.

between the populations. The effect of selection on these traits, which are generally considered to have higher heritability coefficients, was significant. Although the selection pressure on the number of functional nipples was relatively small, the observed progress was highly significant (Table 2). The number of functional nipples is a heritable trait with moderate heritability coefficients (Béjar et al., 1993) so the desired FN can be achieved in several generations of selection. Similarly, the difference in back-fat thickness and lean meat content was highly significant between HPP and NP subpopulation. There are a lot of studies which confirm that heritability coefficients of growth performance traits are middle or high. To endorse the point let us state the results of study done by Bidanel and Ducos (1996), in which they studied the heritability coefficients in Large White population. They computed the heritability coefficients to be 0.23 and 0.43 for average back-fat thickness and lean meat content, respectively. Because of low heritability coefficients, the selection for improvement of prolificacy was considered to be non effective for a long time. Thanks to the use of family information, large population size and particularly the BLUP procedure a remarkable genetic progress for the litter size was made during the last decade of the 20th century. The main progress can be seen in breeding herds not in multiplier herds. Our results suggest that the economic efficiency of multiplier herds could be improved by implementation of additional selection criteria for multiplier herds. The results obtained from literature clearly show that effective selection for stronger symptoms of oestrus (Rydhmer et al, 1994), age at puberty and the interval between weaning and oestrus (Hanenberg et al., 2001); farrowing rate or within-litter variation of piglet birth weight (Quesnel et al, 2008) or maternal behaviour (Gâde et al, 2008) can be obtained. Information concerning all these traits can be monitored on farms and therefore easily utilized as selection criteria. 


\section{Conclusion}

The economic efficiency of multiplier herds depends on the production of sows for commercial herds. Thus the litter size traits or more generally prolificacy are crucial factors which need to be improved. Despite maximal selection pressure, which can be applied in population without negative effects, the progress in litter size traits was insufficient. On the other hand, the progress in traits with high heritability coefficients can be achieved quickly. Therefore some auxiliary selection traits could be incorporated into selection criteria for production of sows for multiplier herd.

\section{Acknowledgment}

Authors would like to express their gratitude to the Ministry of Education, Youth and Sport of the Czech Republic (grant VZ MSM 7088352101) for financing this research.

\section{References}

Alfonso, L, Noguera,J., Babot, D., Estany.J., 1997. Estimates of genetic parameters for litter size at different parities in pigs. Livest. Prod. Sci. 47,149-156. Baruch, E, Weller, J.I., 2009. Incorporation of genotype effects into animal model evaluations when only a small fraction of the population has been genotyped. Animal 3(1), 16-23.

Bejar, F., Rodriguez, M.C., Toro, M,, 1993. Estimation of genetic trends for weaning weight and teat number in Iberian pigs using mixed-model methodology. Livest. Prod. Sci. 33, 239-251.

Bidanel, J.P., Ducos, A,, 1994. Genetic evaluation of Large White and French Landrace pigs for prolificacy using an animal model. J. Rech. Porcine Franc. 26,321-326.

Bidanel, J.P., Ducos, A., 1996. Genetic correlations between test station and onfarm performance traits in Large White and French Landrace. pig breeds. Livest. Prod. Sci. 45, 55-62.
Brenig, B., Brem, G., 1992. Molecular cloning and analysis of the porcine "halothane" gene. Arch. Tierz. 35,129-135.

Distl, 0., 2007. Mechanisms of regulation of litter size in pigs on the genome level. Rep rod. Domest. Anim. 42,10-16.

Gäde, S., Bennewitz, J., Kirchner, K., Looft, H,, Knap, P.W., Thaller, G., Kalm, E., 2008. Genetic parameters for maternal behaviour traits in sos. Livest. Sci. 114,31-41.

Hanenberg, E.H.A.T., Knol, E.F., Merks, J.W.M., 2001. Estimates of genetic parameters for reproduction traits at different parities in Dutch Landrace pigs. Livest Prod. Sci. 69 (2), 179-186.

Hermesch, S., Luxford, B.G., Graser, H.U., 2000. Genetic parameters for lean meat yield, meat quality, reproduction and feed efficiency traits for Australian pigs. 3. Genetic parameters for reproduction traits and genetic correlations with production, carcass and meat quality traits. Livest. Prod. Sci. 65, 261-270.

Mulder, H.A., Bijma, P., 2005. Effects of genotype $x$ environment interaction on genetic gain in breeding programs. J. Anim. Sci. 83, 49-61.

Piyasatian, N., Fernando, R.L., Dekkers, I.C.M., 2008. Introgressing multiple QTL in breeding programmes of limited size. J. Anim. Breed. Genet. 125 (1), 50-56.

Rydhmer, L., Eliasson-Sellinng, L, Johansson, K,, Stern, S., Andersseon, K., 1994. A genetic study of oestrus symptoms at puberty and their relationship to growth and leanness in gilts. J. Anim. Sci. 72,1964-1970.

Weigel, K.A., Rekaya, R., Zwald, N.R., Fikse, W.F., 2001. International genetic evaluation of daily sires using a multiple-trait model with individual animal performance records. J. Dairy Sci. 84, 2789-2795.

Wilton, JW. Goddard, M.E. 1996. Selection for carcass and feedlot traits considering alternative slaughter endpoints and optimised management $\mathrm{J}$. Anim. Sci. 74, 37-45.

Wolf, J., Zakova, E., Groeneveld, E., 2008. Within-litter variation of birth weight in hyperprolific Czech Large White sows and its relation to litter size traits, stillborn piglets and losses until weaning. Livest. Sci. 115, 195-205.

Wolfova, M., Nitter, G., Wolf, J., Fiedler, J., 2001. Impact of crossing system on relative economic weights of traits in purebred pig production. J. Anim. Breed. Genet 118, 389-402.

Quesnel, H., Brossard, L., Valancogne, A., Quiniou, N,, 2008. Influence of some sow characteristics on within-litter variation of piglet birth weight. Animal 12 (2), 1842-1849. 